\title{
INVESTIGATING THE RELATIONSHIP BETWEEN PRIMARY NOCTURNAL ENURESIS WITH DAILY URINARY PROBLEMS AND GENERALIZED ANXIETY DISORDER
}

\author{
Mansoreh Sadat Azimi' ${ }^{1}$, Ali Arjmand Shabestari², Parsa Yousefichaijan ${ }^{3}$, Bahman Salehi $^{4}$, Danial Habibi ${ }^{5}$ \\ ${ }_{1}^{1}$ Medical Student, Department of Paediatrics, Arak University of Medical Sciences, Arak, Iran. \\ ${ }^{2}$ Assistant Professor, Department of Paediatrics, Arak University of Medical Sciences, Arak, Iran. \\ ${ }^{3}$ Professor, Department of Paediatrics, Arak University of Medical Sciences, Arak, Iran. \\ ${ }^{4}$ Professor, Department of Paediatrics, Arak University of Medical Sciences, Arak, Iran. \\ ${ }^{5}$ Lectureship, Department of Paediatrics, Arak University of Medical Sciences, Arak, Iran.
}

\section{BACKGROUND}

ABSTRACT

Generalized anxiety disorder is considered to be one of the most common disorders in children and is associated with diseases such as primary nocturnal enuresis. Primary nocturnal enuresis is one of the most common diseases in children that can cause life problems. The pathogenesis of this disease is multifactorial and may be due to maturation latent cortical mechanisms or psychiatric illnesses. Therefore, a case-control study is designed to investigate the relationship between primary nocturnal enuresis, daily urinary problems and anxiety disorder.

\section{METHODS}

This is a case-control study. The population under study was children aged 5 to 15 years old with non-monosymptomatic nocturnal enuresis, which was referred to the paediatric clinic of Amir Kabir Hospital in Arak, Iran. The Screen for Child Anxiety Related Disorders (SCARED) questionnaire was completed by the parents of these children. After data collection and confirmation based on the diagnostic criteria of the generalized anxiety disorder in 5DSM, the results were analysed by SPSS software version 22 and $p$ value $<0.05$ was defined as a significant difference.

\section{RESULTS}

A total of 200 children entered the study and were assigned in to two groups. 100 children were enrolled in the case group and 100 children in the control group. There was a significant difference between the generalized anxiety and anxiety disorders in both case and control groups, but there was no significant difference in the severity of anxiety.

\section{CONCLUSIONS}

Regarding the fact that the common anxiety disorder in children causes primary nocturnal enuresis and daily urinary problems compared to healthy children, it can be concluded that treatment for this disorder reduced or completely treated primary nocturnal enuresis.

\section{KEY WORDS}

Generalized Anxiety Disorder, Primary Nocturnal Enuresis, Urinary Problems, Children

HOW TO CITE THIS ARTICLE: Azimi MS, Shabestari AA, Yousefichaijan P, et al. Investigating the relationship between primary nocturnal enuresis with daily urinary problems and generalized anxiety disorder. J. Evolution Med. Dent. Sci. 2019;8(30):24292433, DOI: $10.14260 /$ jemds/2019/531

\section{BACKGROUND}

Generalized anxiety disorder (GAD) is one of the most common disorders in children and adolescents, and is characterized by extreme anxiety and anxiety about various events and activities; therefore, anxious thoughts prevent the person from focusing on the work ahead.(1) Studies have shown that multiple physical illnesses are associated with this psychiatric disorder, and diagnosis and treatment of this disease are essential, including nocturnal enuresis.(2) Nocturnal enuresis is one of the most common problems with childhood.(3)

'Financial or Other Competing Interest': None.

Submission 07-04-2019, Peer Review 09-07-2019,

Acceptance 15-07-2019, Published 29-07-2019.

Corresponding Author:

Ali Arjmand Shabestari,

Department of Paediatrics,

Arak University of Medical Sciences,

Arak, Iran.

E-mail: aliarjmand1@yahoo.com

DOI: $10.14260 /$ jemds $/ 2019 / 531$

\section{(c) $\underset{\mathrm{BY}}{\mathrm{NC} \mathrm{ND}}$}

This disorder is known as an excessive urination during sleep. It typically occurs at an age when bladder control usually begins. Night-time bedwetting is diagnosed when involuntary urination is at least twice a week for three consecutive months and the child's age is at least five years old.(4) Nocturnal enuresis is seen in $15 \%$ of five-year-old children, with an average $15 \%$ of children experiencing selfhealing every day. Only $1 \%$ of the patients will still exhibit persistence of nocturnal enuresis into adulthood.(4) Primary nocturnal enuresis is an international health problem and should be addressed seriously.(5) The pathogenesis of this disease is multifactorial and may be due to delayed functional maturation of cortical mechanisms or psychiatric disorders. (6) Sleep disorder, nocturnal urination and having a smaller bladder are listed as three major causes of nocturnal enuresis. However, various studies including factors affecting nocturnal enuresis, including low bladder capacity, deep sleep, positive family history, constipation, chronic renal failure, hyperthyroidism, urinary tract infection, parasitic infection, adenoid, blocked eustachian tubes, diabetes mellitus, the illness of the Sickle cell disease, stressful life experiences (catastrophic events), genetics, and male sex.(3) 
Clinical symptoms of this disorder are frequent urination with urinary burning, urinating during awakening, urinary incontinence, and urge incontinence, as well as squatting and pressure on the perineal wall to prevent the flow of urine out of the body.(7) As previously indicated, mothers of children with early nocturnal enuresis have a lower quality of life.(8) Previous studies have shown that among children with primary nocturnal enuresis, mental problems, anxiety and depression are the most frequent, and problems with decreased attention and hyperactivity disorder have been less frequent.(9) There is also a direct relationship with depression and anxiety, although its relationship with depression is more than anxiety.(10) Regarding to the high prevalence of primary nocturnal enuresis and its unavoidable effects on quality of life and the common relationship between primary nocturnal enuresis and generalized anxiety disorder, psycho-behavioural problems can be considered as an important issue in urinary disorders; therefore, the treatment of generalized anxiety disorder can lead to the removal of primary nocturnal enuresis. Therefore, the aim of this study was to determine the relationship between primary nocturnal enuresis and daily urinary problems and anxiety disorder.(11,12)

\section{METHODS}

This case-control study was conducted on children aged 5 to 15 years with non-monosymptomatic childhood nocturnal enuresis who did not have any underlying illness and chronic drug use and referred to the paediatric clinic of Amir Kabir Hospital, Arak, Iran. The control group was selected from the children, brothers, relatives of the children in the case group or those who are referred to the hospital for other reasons. (13) The group is identical with these children in terms of age, sex, economic status, culture, family, and the number of siblings. Data collection was performed through questionnaires and interviews.

Inclusion criteria included 1 . Primary nocturnal children 2, 5 to 15 years old, 3, not having physical illness, 4 . Not having mental disorders and mental retardation

Exclusion criteria included All children who did not want to participate in the study.

After completing the informed consent form, they entered the study and completed the anxiety disorder questionnaire. Using the data of the questionnaire, the prevalence of generalized anxiety among the children with nonmonosymptomatic childhood nocturnal enuresis was examined and compared with the control group. In this study, 100 children with primary nocturnal enuresis and 100 controls were evaluated. (14) The relationship between nocturnal enuresis and generalized anxiety disorder in children was assessed. In this research, we tried to reconcile the demographic information including age, gender, number of children and the presence of parents in the family. The level of anxiety was determined based on the SCARED screening for child anxiety related emotional disorders (SCARED), and the diagnosis was performed based on the Diagnostic and Statistical Manual of Mental Disorders (DSM5). Information was submitted to the psychiatrist for confirmation of diagnosis.(15)

\section{Sample Size Estimation}

$\mathrm{n}$

$$
\begin{aligned}
& =\frac{\left[z_{1-\frac{\alpha}{2}} \sqrt{(\mathrm{r}+1) \mathrm{p}(1-\mathrm{p})}+\mathrm{z}_{1-\beta} \sqrt{r p_{1}\left(1-p_{1}\right)+p_{2}\left(1-p_{2}\right)}\right]^{2}}{\mathrm{r}\left(p_{2}-p_{1}\right)^{2}} \\
& n \geq \frac{n^{\prime}}{4}\left[1+{\sqrt{\left.1+{ }^{2(\mathrm{r}+1)} / \text { n' }^{\prime}\left|p_{2}-p_{1}\right|\right)^{3}}}^{2}\right.
\end{aligned}
$$

Alpha $(\alpha)=0.05$

Beta $(\beta)=0.2$

Proportion in group $1=0.389$

Proportion in group $2=0.596$

Ratio (Group 2/Group 1)

Number of case group samples: 100 Number of control group samples: 100

\section{Validity and Reliability of the Questionnaire}

Repeated studies have shown that the main scale and subscales of this questionnaire were measured by scale and subscales of other tools such as Spence Children's Anxiety Scale( $r$ $=0.48)$, multi-dimensional children's anxiety scale $(r=0.81)$ and children's anxiety scale $(r=0.85)$ have a high correlation, which indicates the convergence validity of this questionnaire.

\section{Data Analysis}

For statistical analysis, all data were entered into SPSS version 22. In inferential statistics, t-test and chi-square tests were used for analysis of variables at the 5\% significance level.

\section{Ethical Considerations}

This research was performed after approval by the Arak Medical University Ethics Council. All participants in this project, both the patient group and the control group, were interred study by their discretion after completing the informed consent form. Informed consent was obtained from all parents. All information of individuals is also kept confidential and data is reported in general. Subjects who did not want to participate in this study were excluded. In this study, declaration of Helsinki and the ethics statement of Arak University of Medical Sciences were considered.

\section{RESULTS}

A total of 200 patients were enrolled in the study. Age data in case group were based on mean (7.2), standard deviation (1.7), highest age (13 years) and lowest age (5 years). In the control group, the mean (7.3), standard deviation (1.84), the highest age (13 years) and the lowest age (5.5 years) was recorded. In the case group, the number of boys and girls was recorded to be 61 and 39, respectively, and it was 60 and 40 in the control group, respectively.

Table 1 shows the number of children in two groups. In the case group, the number of single, double, triple and fourperson children were recorded to be 25 (26.9\%), 25.5\% (54.8\%), 51 (15.1\%), $14(15.1 \%)$ and $3(3.2 \%)$, respectively. In the control group, the number of single, double, triple and six-person children were 25 (26.3\%), 44 (46.3\%), 25 (26.3\%), and 1 (1.1\%), respectively. Based on the finding presented herein, the mother's job in the case group was as followed; housewife $(63 ; 72.4 \%)$, employee $(17.3 ; 19.5 \%)$, 
freelance $(3 ; 3.4 \%)$, psychologist $(1 ; 1.1 \%)$, physician $(1$; $1.1 \%)$ and secretary $(2 ; 2.3 \%)$. The control group had 52 (70.3\%) housewives, followed by employee $(15,20.3 \%)$, freelance $(4 ; 45.4 \%)$, secretary $(1 ; 1.4 \%)$ and engineer $(2$; $2.7 \% ; 2$ ), (Table 2).

Fathers occupation in the case group are freelance (52; $53.6 \%)$, employee $(30 ; 30.9 \%)$, farmer $(5 ; 5.2 \%)$, hospital secretary $(1 ; 1 \%)$, unemployed $(2 ; 2.1 \%)$, engineer $(3 ; 3.1 \%)$, director $(2 ; 2.1 \%)$, animal husbandry $(1 ; 1 \%)$ and pilot $(1$; $1 \%)$. In the control group, the number of jobs was as follows:

Freelance (45; 45.9\%), employee (33; 33.7\%), Farmer (8; $8.2 \%)$, Engineer (1; 1\%), Managing director $(2 ; 2 \%)$, Pilot 4 ; 4.1), Retired (2; $2 \%)$, Businessman (2;2\%) and Mechanic (1; $1 \%$ ), (Table 3)

\begin{tabular}{|c|c|c|c|}
\hline \multicolumn{2}{|c|}{ Group } & Number & Percent \\
\hline \multirow{3}{*}{ Case } & 1 person & 25 & $26.9 \%$ \\
\cline { 2 - 4 } & 2 persons & 51 & $54.8 \%$ \\
\cline { 2 - 4 } & 3 persons & 14 & $15.1 \%$ \\
\cline { 2 - 4 } & 4 persons & 3 & $3.2 \%$ \\
\hline \multirow{3}{*}{ Control } & 1 person & 25 & $26.3 \%$ \\
\cline { 2 - 4 } & 2 persons & 44 & $46.3 \%$ \\
\cline { 2 - 4 } & 3 persons & 25 & $26.3 \%$ \\
\cline { 2 - 4 } & 6 persons & 1 & $1.1 \%$ \\
\hline \multicolumn{2}{|c|}{ Table 1. Frequency of Children in Control and Case Group } \\
\hline
\end{tabular}

\begin{tabular}{|c|c|c|c|}
\hline \multicolumn{2}{|c|}{ Group } & Number & Percent \\
\hline \multirow{4}{*}{ Case } & preliminary & 4 & $4.9 \%$ \\
\cline { 2 - 4 } & Cycles & 4 & $4.9 \%$ \\
\cline { 2 - 4 } & Diploma & 41 & $50 \%$ \\
\cline { 2 - 4 } & Advanced Diploma & 9 & $11 \%$ \\
\cline { 2 - 4 } & Bachelor & 23 & $28 \%$ \\
\cline { 2 - 4 } & Doctor & 1 & $1.2 \%$ \\
\hline \multirow{4}{*}{ Control } & preliminary & 3 & $5.6 \%$ \\
\cline { 2 - 4 } & Cycles & 2 & $3.1 \%$ \\
\cline { 2 - 4 } & Diploma & 23 & $11.1 \%$ \\
\cline { 2 - 4 } & Advanced Diploma & 6 & $35.2 \%$ \\
\cline { 2 - 4 } & Bachelor & 19 & $1.9 \%$ \\
\cline { 2 - 4 } & Doctor & 1 & \multicolumn{2}{|c|}{1} \\
\hline Table 2. Frequency of Maternal Education in Case and Control Group \\
\cline { 2 - 4 }
\end{tabular}

\begin{tabular}{|c|c|c|c|}
\hline \multicolumn{2}{|c|}{ Group } & Number & Percent \\
\hline \multirow{4}{*}{ Case } & preliminary & 6 & $7 \%$ \\
\cline { 2 - 4 } & guidance & 1 & $1.2 \%$ \\
\cline { 2 - 4 } & Cycles & 4 & $4.7 \%$ \\
\cline { 2 - 4 } & Diploma & 33 & $38.4 \%$ \\
\cline { 2 - 4 } & Advanced Diploma & 5 & $5.8 \%$ \\
\cline { 2 - 4 } & Bachelor & 31 & $36 \%$ \\
\cline { 2 - 4 } & Master's degree & 6 & $7 \%$ \\
\hline \multirow{5}{*}{ Control } & preliminary & 5 & $7.1 \%$ \\
\cline { 2 - 4 } & guidance & 1 & $1.4 \%$ \\
\cline { 2 - 4 } & Cycles & 1 & $1.4 \%$ \\
\cline { 2 - 4 } & Diploma & 24 & $34.3 \%$ \\
\cline { 2 - 4 } & Advanced Diploma & 9 & $35.7 \%$ \\
\cline { 2 - 4 } & Bachelor & 25 & $7.1 \%$ \\
\cline { 2 - 4 } & Master's degree & 5 & \\
\hline Table 3. Frequency of Father's Education in Case and Control Group \\
\cline { 2 - 4 }
\end{tabular}

\begin{tabular}{|c|c|c|c|}
\hline Anxiety Disorder & \multirow{2}{*}{$\mathrm{p}$-Value $=0.001$} \\
\hline No & Yes & \multirow{2}{*}{ Group } \\
\hline 78 & 22 & Case & Control \\
\hline 94 & 6 & Table 4. Frequency of Anxiety Disorder \\
\hline \multicolumn{3}{|c|}{} \\
\hline
\end{tabular}

\begin{tabular}{|c|c|c|c|c|}
\hline \multirow{2}{*}{ Group } & \multicolumn{3}{|c|}{ Frequency of Anxiety Disorder } & \multirow{2}{*}{ p } \\
\cline { 2 - 4 } & Mild & Moderate & Severe & \multirow{2}{*}{0.368} \\
\hline Case & $\mathbf{1 0}$ & $\mathbf{4}$ & $\mathbf{8}$ & \\
\hline Control & $\mathbf{2}$ & $\mathbf{3}$ & $\mathbf{1}$ & \\
\hline \multicolumn{4}{|c|}{ Table 5. Frequency of Anxiety Disorder } \\
\hline
\end{tabular}

\begin{tabular}{|c|c|c|c|}
\hline \multirow{2}{*}{ Group } & Frequency of Generalized Anxiety Disorder & \multirow{2}{*}{ p } \\
\cline { 2 - 3 } & Yes & No & \multirow{2}{*}{0.001} \\
\hline Case & 17 & 83 & \\
\hline Control & 3 & 97 \\
\hline \multicolumn{2}{|c|}{ Table 6. Frequency of Generalized Anxiety Disorder } \\
\hline
\end{tabular}

Chi-square test was used to evaluate the frequency of anxiety disorder (Table 4). In the case group, 22 children had anxiety disorder, and this number was reduced to 6 in the control group, where the difference was statistically significant $(p=0.001)$, indicating that anxiety disorder increased early nocturnal enuresis. According to the frequency of anxiety severity in the case group (Table 5), out of 22 children, 10 were mildly anxious, followed by moderate severity ( 4 subjects) and severe anxiety disorder ( 8 subjects).

In the control group, out of a total of 6 children, 2 were mild, followed by moderate ( 3 subjects) and severe anxiety disorder (1 subjects). Chi-square test was used to determine the severity of anxiety

Where there was no statistically significant difference between the groups $(p=0.368)$ and indicating that the severity of anxiety does not affect the early nocturnal enuresis.

As indicated in Table 6, the frequency of anxiety disorder in the case group was determined to be 17 , while this number has decreased to 3 in the control group. Chi-square test demonstrated that this difference was statistically significant between two groups $(\mathrm{p}<0.05)$, which indicates that generalized anxiety disorder causes an increase in primary nocturnal enuresis.

\section{DISCUSSION}

Nocturnal enuresis is the most commonly diagnosed paediatric urological disorder in children.(16) This disorder has different definitions in different cultures and generally refers to urinary incontinence after age 5 . The prevalence of this disorder has decreased with the age of the child, and it is twice the number of girls.(17) Various reasons have been raised for this disorder, and various therapies have been considered for this, but the presence of some behavioral and psychiatric disorders with the child's nocturnal enuresis has led to a number of studies.

The frequency of anxiety disorder, frequency of generalized anxiety disorder, and severity of anxiety disorder were assessed in this study. In the current study, 200 children aged 5 to 15 years old entered the study. The control group was similar to the case group in terms of age, sex, and demographic information. Furthermore, the frequency of nocturnal enuresis was higher in boys (61\%) than girls (39\%), which is similar to that of many other studies in other areas,(18) although some studies have highlighted high frequency of nocturnal enuresis in girls.(19) The frequency of nocturnal enuresis in this study was determined as $22 \%$ based on the DSM5 criteria, which was higher than the results of research carried out in other countries and regions, including Egypt(18) with a frequency of $10.13 \%$, Turkey $(16.2 \%)$ (20). India $(11.13 \%),{ }^{(21)}$ while its prevalence in Nigeria was found to be $23.2 \%$, and therefore more likely to be closer to our study. In this study, primary nocturnal enuresis was associated with family history. In this regard, the results of other studies have identified family history as one of the factors affecting the nocturnal enuresis which is likely to be hereditary. For example, in a study conducted by Gure in 2004 on 1576 children, students were randomly selected from 14 elementary schools located in seven different regions of Istanbul. The relationship between prevalence of enuresis and risk factors as well as urinary pathology was evaluated using Chi-square's test and logistic regression analysis. Based on the aforementioned study, there was a significant relationship between nocturnal 
enuresis and family history, (22) which is also consistent with the results of this study.

In this study, out of 100 children with enuresis (case group), $22 \%$ had anxiety disorder, and $6 \%$ of control group had a history of anxiety disorder, where there was a significant difference between groups. It can be concluded that the anxiety was leading to an increase in nocturnal enuresis in children.

In a similar study conducted by Mohammad Por and his colleagues in a group of students in 2012, they found that there was a significant relationship between mental and emotional problems with the frequency of nocturnal enuresis. As children who are exposed to fear, stress, and anxiety due to different factors (Such as seeing scary films), they are more likely to suffer from nocturnal enuresis.(23) Another study indicated that stress and psychological factors and nocturnal enuresis in children are closely related to each other. Primary nocturnal children are markedly stressful, suffering from psychiatric disorders, and most of these disorders include symptoms of anxiety that are consistent with the results obtained in this study.(24) Given the fact that p-value was obtained $(\mathrm{p}=0.001)$ in the assessing of generalized anxiety disorder, the results indicated the effect of generalized anxiety disorder in the group of children with enuresis, which increased the primary nocturnal enuresis in children.

It is suggested that anxiety in the third year is frequently the major factor causing children's failure to have learnt nocturnal bladder control before they enter the period of difficult learning. The bedwetting persists as 'primary' enuresis; the anxiety is usually transient. In a study by Kieth on 8,242 primary urinary children, it has bee reported that children had generalized anxiety $(10.5 \%)$, separation anxiety (8\%), social anxiety (7\%), physical anxiety (14.1\%), depression (14.2\%), hyperactivity $(17.6 \%)$, attention deficit (8.8\%), (25). In this study, $17 \%$ of children with GAD had nocturnal enuresis while $3 \%$ of healthy children were suffering from this disorder; it is worth noting that the results of these two studies were consistent. Regarding the value of p-value (0.386), the severity of anxiety was not significantly different between affected and non-affected subjects. It indicates that the severity of anxiety is not different in patients with primary nocturnal enuresis and healthy children. Perhaps this contradiction is due to differences in research environments and low sample size.

\section{CONCLUSIONS}

Given the low sample size, this study cannot be generalized to the entire population, but according to the results obtained in this study and similar studies, the prevalence of anxiety disorders, especially the generalized anxiety disorder, is higher in children with primary non-monosymptomatic enuresis. Therefore, it can be concluded that anxiety can be one of the causes of diarrhoea. Its timely treatment can prevent the occurrence of enuresis and its many consequences. It can also be said that enuresis treatment is capable of reducing the amount of anxiety, especially generalized anxiety disorders in children.

\section{REFERENCES}

[1] Mohammadzadeh A, Jomehri-Kohneshahri R. The comparison of personality traits, trait - state anxiety and existential anxiety among patients with generalized anxiety disorder and normal people. Journal of Clinical Psychology 2016;8(29):83-91.

[2] Vijay K, Avasthi A, Grover S. A study of worry and functional somatic symptoms in generalized anxiety disorder. Asian Journal of Psychiatry 2014;11:50-2.

[3] Cobussen-Boekhorst HJ, van Genugten LJ, Postma J, et al. Treatment response of an outpatient training for children with enuresis in a tertiary health care setting. J Pediatr Urol 2013;9(4):516-20.

[4] Alkot M, Deeb M. Nocturnal enuresis among school children in Menofia Governorate, Egypt: a hidden problem. J Am Sci 2012;8(1):327-34.

[5] Piyasil V, Udomsup J. Enuresis in children 5-15 years at Queen Sirikit National Institute of Child Health. J Med Assoc Thai 2002;85(1):11-16.

[6] Karen J. Nelson essentials of paediatrics. $7^{\text {th }}$ edn. Tehran: Elsevier 2015.

[7] Hajizadeh N, Hassanzad M. Study of symptoms in patients with voiding dysfunction and their response to treatment. Iran J Pediatr 2006;16(3):11-7.

[8] Egemen A, Akil I, Canda E, et al. An evaluation of quality of life of mothers of children with enuresis nocturna. Pediatr Nephrol 2008;23(1):93-8.

[9] Yousefi P, Salehi B, Firouzifar MR, et al. The correlation between attention deficit hyperactivity disorder and enuresis in children with nocturnal enuresis. J- Isfahan Med School 2012;30(12):1-8.

[10] Breyer BN, Shindel AW, Erickson BA, et al. The Association of depression, anxiety and nocturia: a systematic review. J Urol 2013;190(3):953-7.

[11] McKenna PH, Herndon CD. Voiding dysfunction associated with incontinence, vesicoureteral reflux and urinary tract infection. Curr Opin Urol 2000;10(6):599-606.

[12] Currran MJ, Kaefer M, Peters C, et al. The overactive bladder in childhood long term results with conservative management. J Urol 2000;163(2):574-7.

[13] Yousefi P, Firouzifar MR, Dorreh F. Growth and development in 6-year-old children with and without primary nucturnal enuresis. J ZUMS 2013;20(82):94-9.

[14] Pfister C, Dacher JN, Gaucher S, et al. The usefulness of a minimal urodynamic evaluation and pelvic floor biofeedback in children with chronic voiding dysfunction. Br J Urol Int 1999;84(9):1054-7.

[15] Paul NI, Alikor E, Anochie IC. Factors associated with enuresis among primary school children in Port Harcourt. Niger J Paediatr 2013;40(4):370-4.

[16] Lottmann HB, Alona I. Primary monosymptomatic nocturnal enuresis in children and adolescents. Int J Clin Pract Suppl 2007;61(155):8-16.

[17] Kliegman RM, Behrman RE, Jenson HB, et al. Nelson textbook of Paediatrics. Philadelphia, PA: W.B. Saunders 2011;22(14):4-9.

[18] Ismail A, Abdelbasser K, Abdel-Moneim M. Prevalence and risk factors of primary nocturnal enuresis in primary school children in Qena Governorate-Egypt. Egypt J Neurol Psychiat Neurosurg 2013;50(2):163-9.

[19] Aljefri HM, Basurreh OA, Yunus F, et al. Nocturnal enuresis among primary school children. Saudi J Kidney Dis Transpl 2013;24(6):1233-41. 
[20] Dolgun G, Savaser S, Balci S, et al. Prevalence of nocturnal enuresis and related factors in children aged 5-13 in Istanbul. Iran J Pediatr 2012;22(2):205-12.

[21] Solanki AN, Desai SG. Prevalence and risk factors of nocturnal enuresis among school age children in rural areas. Int J Res Med Sci 2014;2(1):202-5.

[22] Gur E, Turhan P, Can G, et al. Enuresis: prevalence, risk factor and urinary pathology among school children in Istanbul, Turkey. Paediatrics International 2004;46(1):58-63.
[23] Mohammadpour A, Moghaddam BM, Jani S, et al. Survey of enuresis frequency and its associated factors among school children. Ofogh-e-Danesh. Journal of Gonabad University Sciences 2012;18(3):37-44.

[24] Von Gontard A. Dose psychological stress affect LUT function in children? Neurourol Urodynamic 2012;31(3):344-8.

[25] Kieth MR. A frequent factor in the origins of primary nocturnal enuresis: anxiety in the third year of life. Developmental Medical and Child Neurology 1968;10(4):465-70. 